\title{
Computational analysis of hybrid heating of a heterogeneous core-shell configuration for improving temperature uniformity
}

Análisis computacional del calentamiento híbrido de una configuración heterogénea de núcleo-caparazón para mejorar la uniformidad de la temperatura

\author{
Ivan Amaya ${ }^{1}$, Juan David Bastidas Rodríguez ${ }^{2}$, Carlos Rodrigo Correa Cely ${ }^{3 *}$ \\ ${ }^{1 *}$ Doctor en ingeniería electrónica, iamaya2@tec.mx, ORCID: 0000-0002-8821-7137, Escuela de Ingeniería y Ciencias, Tecnológico de Monterrey, Monterrey \\ Colombia, México. \\ ${ }^{2}$ Doctor en ingeniería eléctrica y electrónica, jubastidasr@unal.edu.co, Universidad Nacional de Colombia, Manizales, Colombia \\ ${ }_{3}^{3}$ Doctor en ingeniería, crcorrea@saber.uis.edu.co, ORCID: 0000-0002-6507-1809, Universidad Industrial de Santander, Bucaramanga, Colombia.
}

Cómo citar: G. F. García-Sánchez, J. L. Chacón-Velasco, D. A. Fuentes-Díaz, J. E. Jaramillo-Ibarra and J. R. MartínezMorales, "CFD modelling of biomass boilers - a review of the state of the art". Respuestas, vol. 25, no. 3, 110-124, 2020.

Received on June 22, 2020 - Approved on October 23, 2020.

Keywords:

Microwaves; thermal radiation; hybrid thermal treatment; coreshell; transient state.

\section{ABSTRACT}

Throughout this study, we propose using hybrid heating (microwaves - thermal radiation) on a heterogeneous structure. Our goal is to improve the effectivity of its thermal treatment. We analyze a core-shell assembly with different thermal and electrical properties. A solid sphere makes up the core of the arrangement. Such a core is surrounded by three layers of different materials. Because of the properties of the original system, we propose modifying the core so that it absorbs microwaves. The layers are all homogeneous and microwave transparent. The first two exhibit a low thermal conductivity, while the outermost one is a good thermal conductor. We also propose adding a thin layer of susceptor between the first two layers, striving to alleviate the low thermal conduction problem. Furthermore, the dielectric loss constant of this new layer is temperature-dependent. We assume that the composed sphere hangs within the electromagnetic cavity and continuously rotates, so it homogeneously receives microwaves and thermal radiation (from an electrical resistance). Thus, the thermal model is given by a set of time-dependent partial differential equations. Transient temperature profiles are analyzed under different experimental scenarios. There is a clear advantage of using the proposed hybrid heating in this particular case.

\section{RESUMEN}

\section{Palabras clave:}

Microondas; radiación térmica; tratamiento térmico híbrido; coreshell; estado transitorio.
A lo largo de este estudio, proponemos utilizar el calentamiento híbrido (microondas - radiación térmica) sobre una estructura heterogénea. Nuestro objetivo es mejorar la eficacia de su tratamiento térmico. Analizamos un conjunto core-shell con diferentes propiedades térmicas y eléctricas. Una esfera sólida constituye el núcleo del conjunto. Dicho núcleo está rodeado por tres capas de diferentes materiales. Debido a las propiedades del sistema original, proponemos modificar el núcleo para que absorba las microondas. Las capas son todas homogéneas y transparentes a las microondas. Las dos primeras presentan una baja conductividad térmica, mientras que la más externa es un buen conductor térmico. También proponemos añadir una fina capa de susceptor entre las dos primeras capas, tratando de paliar el problema de la baja conducción térmica. Además, la constante de pérdida dieléctrica de esta nueva capa depende de la temperatura. Suponemos que la esfera compuesta cuelga dentro de la cavidad electromagnética y gira continuamente, por lo que recibe homogéneamente microondas y radiación térmica (de una resistencia eléctrica). Así, el modelo térmico viene dado por un conjunto de ecuaciones diferenciales parciales dependientes del tiempo. Se analizan los perfiles de temperatura transitorios bajo diferentes escenarios experimentales. La utilización del calentamiento híbrido propuesto presenta una clara ventaja en este caso concreto. 
The application of microwave-based thermal treatment in processes such as chemical reactions have spread the word about such a technique. Among its advantages reside unique features, such as a lowered electrical energy consumption and a fast and controlled heating. This, in turn, allows reducing processing times and energy costs, as well as improving physico-mechanical properties. All of this favors the economy of the process [1] - [4]. Despite its advantages, real application of microwave heating is sometimes limited. This is especially true when certain surface properties are required, which can only be achieved through traditional heating (convection or thermal radiation). Likewise, it is also not appropriate to use microwave heating for all materials and processes. The reason: The process may become unfeasible from an economic point of view.

Microwave processing is favored when the material to be heated exhibits a high complex permittivity (real, $\epsilon^{\prime}$, and imaginary, $\epsilon^{\prime \prime}$, components). These parameters are, in general, temperature and frequency dependent. Such is the case for BaTiO3 and SiC. Hence, it becomes necessary to determine them experimentally. One way of doing so is through the coaxial transmission line (CTL) or the cavity perturbation methods, using a network analyzer [5], [6]. There is also a dependency regarding variables such as sample geometry, porosity and size, as well as the change in their properties and the presence of volatiles, among others. Because of this, it becomes paramount to follow a careful analysis of the experimental data, especially when validating a mathematical model [6] - [9]. It is due to the aforementioned difficulties that hybrid heating represents a handsome alternative. Such a treatment seeks to combine the best of both worlds. Literature reports quite a variety of hybrid heating applications, such as in reactors and ferroelectric synthesis, among others [10][13]. One way of doing hybrid heating is to combine microwaves with thermal radiation. In this work, we simulate such a scenario, assuming that thermal radiation comes from an electrical resistance. Here, we seek to determine whether this approach is feasible for the selected heterogeneous system.

The system selected for treatment in this work is given by a core-shell structure, with four regions of quite different thermal conductivities and dielectric losses. The thermal treatment consists on keeping temperature between 370 and $410^{\circ} \mathrm{C}$. We opted for modifying the core, mixing it with a nano-susceptor $(15 \% \mathrm{w} / \mathrm{w})$. This makes it possible for the core to absorb microwaves, and provides a high thermal conductivity. Moreover, the first layer has a low thermal conductivity. Also, because of problem restrictions, it cannot be mixed with a susceptor. Therefore, we opted for coating it (thus creating a new thin layer) with susceptor and at a maximum thickness of $0.5 \mathrm{~cm}$. Such a layer also has a dielectric loss factor $\left(\varepsilon^{\wedge \prime}(T)\right)$ that changes linearly with temperature. Hence, its internal energy generation is affected. For the next layer, the problem restricts it from being mixed or coated and it has a low thermal conductivity. The outermost layer was also not altered. The proposed hybrid heating system is given by a magnetron that feeds a traditional microwave cavity. Thermal radiation is supplied by an electrical resistance located within the cavity. The resulting mathematical model comes from a global energy balance and it is given by a set of coupled partial differential equations. The model was articulated with one for volumetric heat generation derived from Maxwell equations. The complete model was solved through finite element analysis in MATLAB. In the end, transient temperature profiles were generated. We also generated gradients in all directions as a function of time for some limit scenarios. This allowed us to analyze how effective this strategy actually was.

\section{Thermal model}

\section{The 3D thermal problem}

The final thermal system is composed by a solid internal sphere and four concentric layers. Since such a modified sphere has constant electrical properties $\left(\varepsilon^{\prime} ; \varepsilon^{\prime \prime} ; \tan (\delta)\right)$, it can absorb energy transported by an incident electromagnetic field. For this work, the field is equivalent to microwaves. Layers one and three exhibit a low thermal conductivity, thus inhibiting a homogeneous processing. Nonetheless, the added layer (number two) absorbs microwaves and has a high thermal conductivity. The external layer (number four) 
also is a good thermal conductor. For this work, we assume that contact resistances between layers are negligible. Moreover, we assume that thermophysical properties are time, position, and temperature invariant. Additionally, the sphere is assumed to hover within the electromagnetic cavity and slowly rotates. A mode stirrer is included in the cavity. Hence, the sphere receives uniform radiation from both, microwaves and electrical resistance, on both hemispheres.

\section{Thermal model within the system}

Heat conduction throughout the core-shell system, while it is being subjected to hybrid heating, is analyzed. The heating system is composed by a microwave generator and an electrical resistance that heats the outermost layer. The mathematical model describing heat conduction is given by a set of five coupled timevariable partial differential equations, in spherical coordinates. Thermal conductivities and dielectric loss factors are temperature independent. The solution of the mathematical model allows generation of temperature profiles as a function of position (3D) and time, for each of the four layers, as well as for the solid sphere. The model is given by the energy balance (also known as heat diffusion equation) shown in (1), which is valid for: $r_{i} \leq r \leq r_{i+1}$, with $i=1,2,3,4,5$.

$$
\begin{gathered}
\rho_{i} c_{i} \frac{\partial T_{i}(r ; \mu ; \phi ; t)}{\partial t}=\frac{1}{r^{2}} \frac{\partial}{\partial r}\left(r^{2} k_{i}(T) \frac{\partial T_{i}(r ; \mu ; \phi ; t)}{\partial r}\right)+\frac{1}{r^{2} \sin ^{2} \theta} \frac{\partial}{\partial \phi}\left(k_{i}(T) \frac{\partial T_{i}(r ; \mu ; \phi ; t)}{\partial \phi}\right) \\
+\frac{1}{r^{2} \sin \sin \theta} \frac{\partial}{\partial \theta}\left(\sin \sin \theta k_{i}(T) \frac{\partial T_{i}(r ; \mu ; \phi ; t)}{\partial \theta}\right)+P_{a v}^{\prime \prime \prime}(r ; \theta ; \phi ; t ; \varepsilon(T))
\end{gathered}
$$

Figure 1 shows the standard diagram of the coordinate system. Through a variable change common in literature $(\mu=\cos \theta)$ the initial and boundary conditions become in (2)-(10):

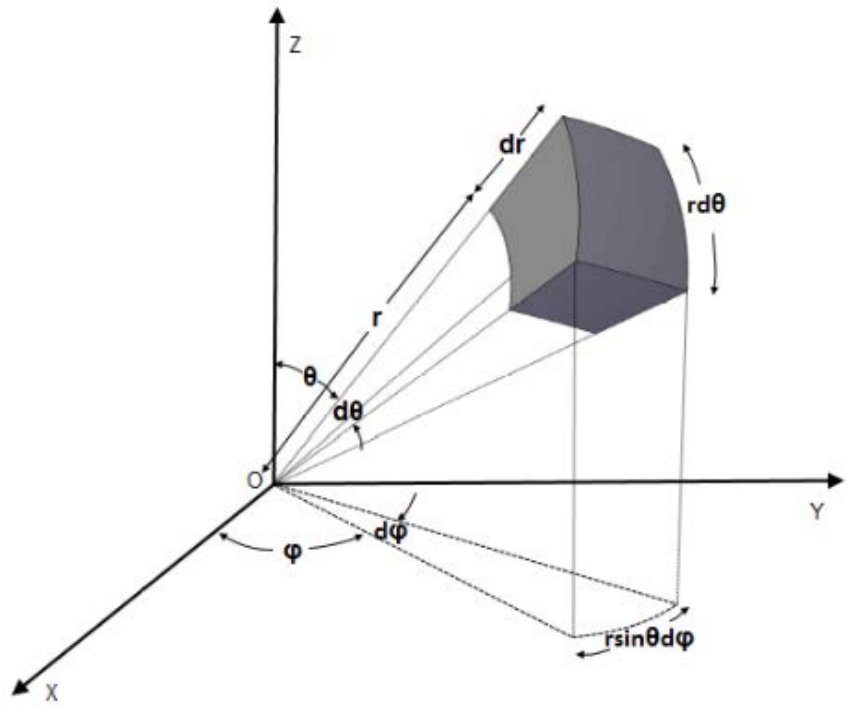

Figure 1. Definition of nomenclature in spherical coordinates Source: Author

Initial conditions:

$$
T_{i}(r ; \mu ; \phi ; t=0)=f_{i}(r ; \mu ; \phi)
$$


Boundary conditions:

1. Direction $r$ and for the core $(i=1)$ :

$$
\frac{\partial T_{1}\left(r_{1} ; \mu ; \phi ; t\right)}{\partial r}=0
$$

2. Direction $r$ for the outermost shell $(i=5)$ :

$$
k_{5} \frac{\partial T_{5}\left(r_{5} ; \mu ; \phi ; t\right)}{\partial r}=q^{\prime \prime}\left(r=r_{5} ; \mu ; \phi\right)
$$

where $q^{\prime \prime}\left(r=r_{5} ; \mu ; \phi\right)$ is the heat flow per unit area that the electrical resistance generates over the external sphere.

3. Temperature continuity on the same sphere $(i=1,2,3,4,5)$ :

$$
T_{i}(r ; \mu=-1 ; \phi ; t)=T_{i}(r ; \mu=1 ; \phi ; t)
$$

4. Heat Flow continuity on the same sphere $(i=1,2,3,4,5)$ :

$$
\frac{\partial T_{i}(r ; \mu=-1 ; \phi ; t)}{\partial \mu}=\frac{\partial T_{i}(r ; \mu=1 ; \phi ; t)}{\partial \mu}
$$

5. Temperature continuity throughout layers $(i=1,2,3,4,5)$ :

$$
T_{i}(r ; \mu ; \phi=0 ; t)=T_{i}(r ; \mu ; \phi=2 \pi ; t)
$$

6. Heat Flow continuity throughout layers $(i=1,2,3,4,5)$ :

$$
\frac{\partial T_{i}(r ; \mu ; \phi=0 ; t)}{\partial \phi}=\frac{\partial T_{i}(r ; \mu ; \phi=2 \pi ; t)}{\partial \phi},
$$

7. Temperature continuity at the interface between core and first layer, as well as between layers $(1: 2 ; 2: 3 ; 3: 4 ; 4: 5)$ :

$$
T_{i}\left(r_{i} ; \mu ; \phi ; t\right)=T_{i+1}\left(r_{i+1} ; \mu ; \phi ; t\right),
$$

8. Heat flow continuity at the interface between core and first layer, as well as between layers $(1: 2 ; 2: 3 ; 3: 4 ; 4: 5)$ :

$$
k_{i} \frac{\partial T_{i}\left(r_{i} ; \mu ; \phi ; t\right)}{\partial \phi}=k_{i+1} \frac{\partial T_{i+1}\left(r_{i+1} ; \mu ; \phi ; t\right)}{\partial \phi},
$$

Conditions 3 and 4 belong to the $\theta$ direction, while 5 and 6 belong to $\phi$. In this case, internal energy generation (i.e. volumetric heat generation) exists for the core $(i=1)$ and for layer two $(i=3)$. This is assumed to be constant with time and position. Here, we will model it as a constant energy flow, transported by electromagnetic waves and exclusively absorbed by nano-susceptors with constant complex permittivity. Other components of the system are described further on. 
The model will be solved under the consideration that thermodynamic properties of the system are position independent (homogeneous isotropic media). Regarding boundary conditions and internal generation, we shall assume them as time independent. We also consider that no component evaporates and that there are no chemical reactions.

\section{Equations modeling microwave interaction}

Power transported by electromagnetic waves and absorbed by the system can be described in (11), (12) y (13), and are known as the three independent Maxwell equations,

$$
\begin{array}{ll}
\nabla \times E=j \omega B & \text { (Faraday law) } \\
\nabla \times H=j \omega D+J & \text { (Maxwell-Ampere law) } \\
\nabla \cdot J=-j \omega \rho_{e} & \text { (Continuity equation) }
\end{array}
$$

It is evident that electric and magnetic fields must simultaneously exist within the cavity, as they interact. Likewise, constitutive equations are required $D=\varepsilon E ; B=\mu H$ and $J=\sigma E$. Complex permittivity of a material is given by (14),

$$
\varepsilon^{*}=\varepsilon^{\prime}-j \varepsilon^{\prime \prime}
$$

Both parameters are temperature and frequency dependent, for most materials. Hence, they are paramount when studying electromagnetic wave penetration and its conversion to thermal energy (heat). Two of the most relevant parameters in microwave-based thermal treatment are: the imaginary part of complex permittivity, also known as dielectric loss constant $\left(\varepsilon^{\prime \prime}\right)$; and the loss tangent ( $\tan \delta=\varepsilon^{\prime \prime} / \varepsilon^{\prime}$ ). The latter represents the ability of a material for converting microwaves into heat. A material with high $\tan \delta$ and $\varepsilon^{\prime \prime}$ will be easier to heat than other with lower values. Higher $\varepsilon^{\prime}$ values indicate a higher wave penetration. Also, high $\varepsilon^{\prime \prime}$ values are linked to a high conversion of energy into heat.

\section{Power generated by microwaves}

Microwave heating implies direct conversion of electromagnetic energy into heat. Integrating the Poynting vector $(S)$ yields the power flow through a closed surface, indicated in (15).

$$
S=E \times H
$$

Using Maxwell current law and considering $\varepsilon^{*}$ and that $J=\sigma E$,

$$
\nabla \times H=\omega \varepsilon_{0} \varepsilon_{e f}^{\prime \prime} E+j \omega \varepsilon_{0} \varepsilon^{\prime} E
$$

where, $\varepsilon_{e f}^{\prime \prime}=\varepsilon^{\prime \prime}+\sigma / \omega \varepsilon_{0}$. Factor $\varepsilon^{\prime \prime}$ involves all losses, except those due to electrical conductivity. Using the conjugate of electric and magnetic fields [14],

$$
(\nabla \times E) \cdot H^{*}-\left(\nabla \times H^{*}\right) \cdot E=-j \omega \mu_{0} \mu^{\prime} H \cdot H^{*}+j \omega \varepsilon_{0} \varepsilon^{\prime} E \cdot E^{*}-\omega \varepsilon_{0} \varepsilon_{e f}^{\prime \prime} E \cdot E^{*}
$$

Using this equation and the definition of average PowerPoint given in (18) [14],

$$
P_{a v}=-\frac{1}{2} \iint_{A} \operatorname{Re}\left[E \times H^{*}\right] \cdot d A=\pi f \varepsilon_{0} \varepsilon_{e f}^{\prime \prime} \iiint_{V}\left(E \cdot E^{*}\right) d V
$$

and, so, electrical power transported by electromagnetic waves depend on the electric field. The latter is variable in space within the cavity. Nonetheless, and since measurement is not straightforward, we will assume it as constant so that, 


$$
P_{a v}^{\prime \prime \prime}=\pi f \varepsilon_{0} \varepsilon_{e f}^{\prime \prime}(T) E_{r m s}^{2}
$$

This power dissipated per volume unit can be given for the sphere in a more general form as shown in (20),

$$
P_{a v}^{\prime \prime \prime}(r ; \theta ; \phi ; t)=\pi f\left[\varepsilon_{0} \varepsilon_{e f}^{\prime \prime}(T) E_{r m s}^{2}+\mu_{0} \mu_{e f}^{\prime \prime}(T) H_{r m s}^{2}\right]
$$

which considers magnetic losses on the material. In both cases, heat will be generated within the sphere. For this work, we will consider that only the electric field interacts with the material of the inner sphere. When solving Maxwell equations, we will consider the boundary conditions of perfectly conducting walls. Because of this, tangential component of the electric field at the air-wall interface is zero.

Power generated by the electrical resistance, $q^{\prime \prime}$ : The electrical resistance is tasked with generating thermal radiation for impacting the external surface of the core-shell structure. The power generated by Joule effect can be calculated as $i^{2} R$.

\section{Materials and methods}

Parameters used for the thermal model are summarized in Table 1, while Figure 2 shows the experimental setup. Besides the electrical resistance and the microwave applicator, a metallic mode stirrer was included

\begin{tabular}{|c|c|}
\hline Parameter & Value or range \\
\hline Sphere and shell radius, $r_{i},[\mathrm{~m}]$ & $0.04 ; 0.06 ; \underline{0.065 ; 0.08 ; 0.12}$ \\
\hline \multirow{4}{*}{$f_{i} * A_{i} \frac{\alpha_{i} g^{\prime \prime \prime}\left(r_{i} ; \mu ; \phi\right)}{k_{i}},\left[K s^{-1}\right]$} & Inner sphere factor $f_{1}=6.91$ \\
\hline & Temperature dependent function \\
\hline & $(\underline{\text { Shell } 2, i=3})$ : \\
\hline & $f_{S 2}(T)=\frac{1}{6} T\left({ }^{\circ} \mathrm{C}\right)-\frac{92}{100}$ \\
\hline \multirow[t]{2}{*}{$f_{s 4} q \equiv$ External heat flux $\left[\mathrm{Wm}^{-2}\right]$} & Factor $f_{3}=f_{s 4}:\left[\begin{array}{lll}0 & a & 4.2\end{array}\right]$ \\
\hline & \\
\hline$f f * \alpha_{1}\left[m^{2} s^{-1}\right]$ & \\
\hline$\alpha_{i}=f f * k_{1} / \rho_{1} c_{1}$ & \\
\hline$\alpha_{1}=0.0021$ & $\alpha_{i}=f f * \alpha_{1}, i=2,3,4,5$ \\
\hline Initial condition, $\left(K,{ }^{\circ} \mathrm{C}\right)$ & $298(25)$ \\
\hline
\end{tabular}
for improving the distribution of the electromagnetic field.

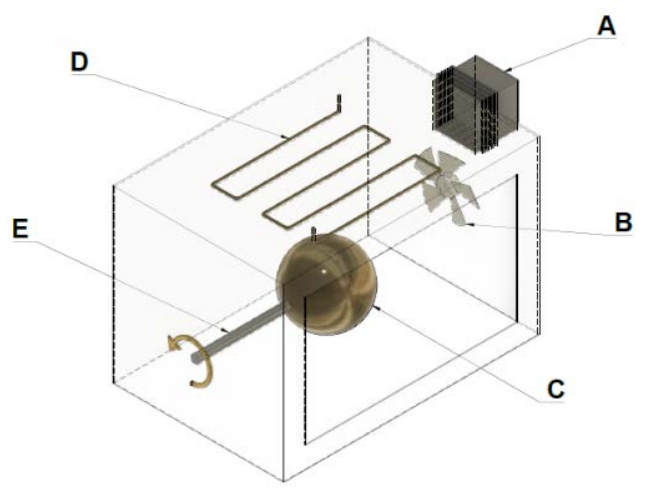

Figure 2. Experimental setup simulated. A: Magnetron, B: Mode stirrer, C: Composite sphere, D: Electrical resistance (grill), E: Rotatory axis Source: Author 


\section{Procedure}

We begin by showing experiments with the original system (i.e. with no added layer nor modified sphere). This is done to grasp an idea about the thermal problem. Afterwards, simulations considering only the electrical resistance are presented. We verify that temperature profiles be symmetric, since the system rotates. We then move on to simulate the effect of having only microwave-based heating. This should generate an inverse temperature profile, meaning that the geometric center of the system will be the hottest point. Finally, we analyze the effect of hybrid heating on temperature profiles at each layer. We consider an operating restriction where the system must be kept between $370-410^{\circ} \mathrm{C}$.

\section{Results and Discussion}

The original system, i.e. the three-layered sphere, did not change from its initial temperature of $25^{\circ} \mathrm{C}$, since no phase absorbs microwaves. By changing composition of the inner sphere, temperature rises. Figure 3a shows the temperature profile exclusively due to microwaves, and assuming a sphere mixed with a nanosusceptor $(15 \% \mathrm{w} / \mathrm{w})$. Temperature profiles show the effect of the first two layers (s1 and s2), which exhibit low thermal conductivity. If we only consider microwave-based heating, it is actually impossible to reach the required temperature range. A similar issue occurs if we only consider the electrical resistance (Figure $3 b$ ). Here, it is possible to reach high temperatures (even beyond the limit of $410{ }^{\circ} \mathrm{C}$ ), but only in the external layer. In both scenarios, thermal conduction plays a major role. However, the temperature reached throughout the system after processing for 200s, is not good enough.

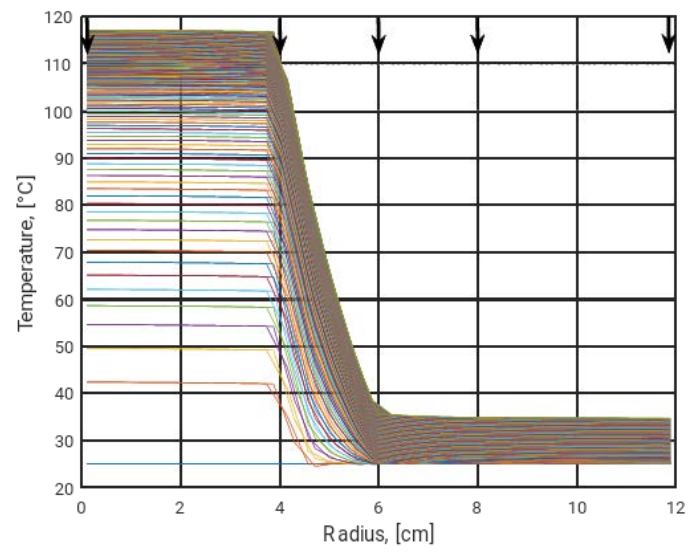

(a)

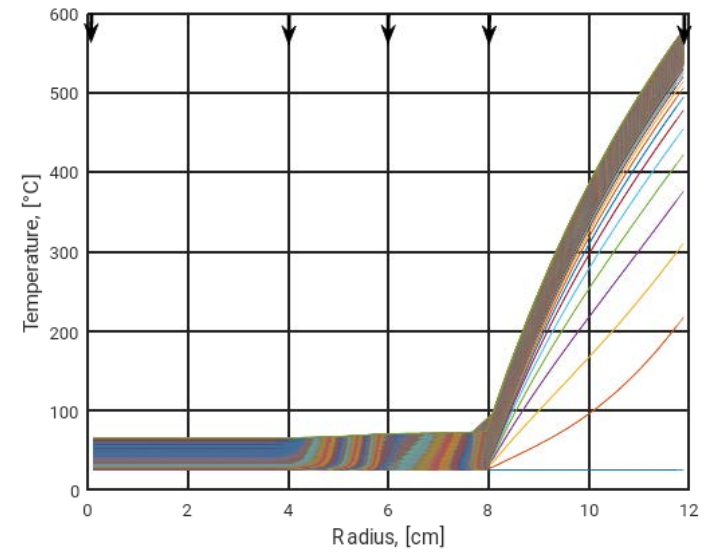

(b)

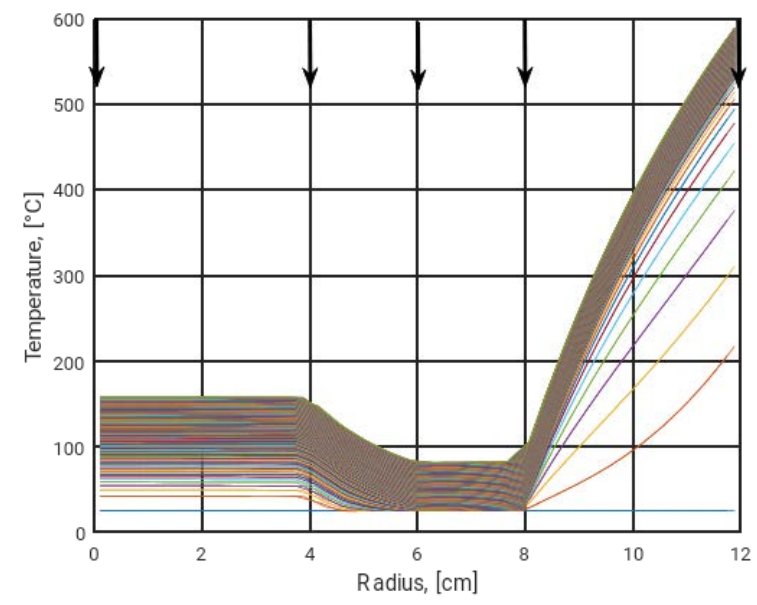

(c)

Figure 3. Temperature profiles after processing for $200 \mathrm{~s}$. a: considering only the magnetron and a factor $f_{1}=6.91$; b: considering only the electrical resistance and a factor $f_{3}=4.2$; $\mathrm{c}$ Hybrid heating. Arrows indicate the limit of each phase in the system 
It is important to remember that the mathematical model is coupled. So, any change in a parameter (i.e. volumetric energy generation or thermal radiation) affect the temperature profile of the whole system. So, it is important to find strategies that achieve valid results that can be reproduced in real life.

Figure 3c shows the results for the hybrid heating. Even so, it is practically impossible to achieve a good enough heating by only changing the composition of the inner sphere. Hence, we proceed to include a thin layer (now called s2) with another nano-susceptor. Such a layer will be placed between the two layers with low thermal conductivity (now called s1 and s3). The reason for this approach is that we are considering the case where the material of the layers cannot be modified. Since we have a new layer, the outermost shell is now called s4.

\section{Considering only the electrical resistance:}

Figure 4 shows the temperature profile of the core and the four shells. Because of the high conductivity in the core, it does not exhibit any temperature gradient. Hence, its planar profile. A different scenario occurs in the surrounding layers. Here, temperature gradients are steep, especially in the first two layers (now called s1 and s3). This is due to their low thermal conductivities. The added thin layer (s2) is also present but has a low gradient. Temperature differences between $150-200{ }^{\circ} \mathrm{C}$ are present throughout the system.

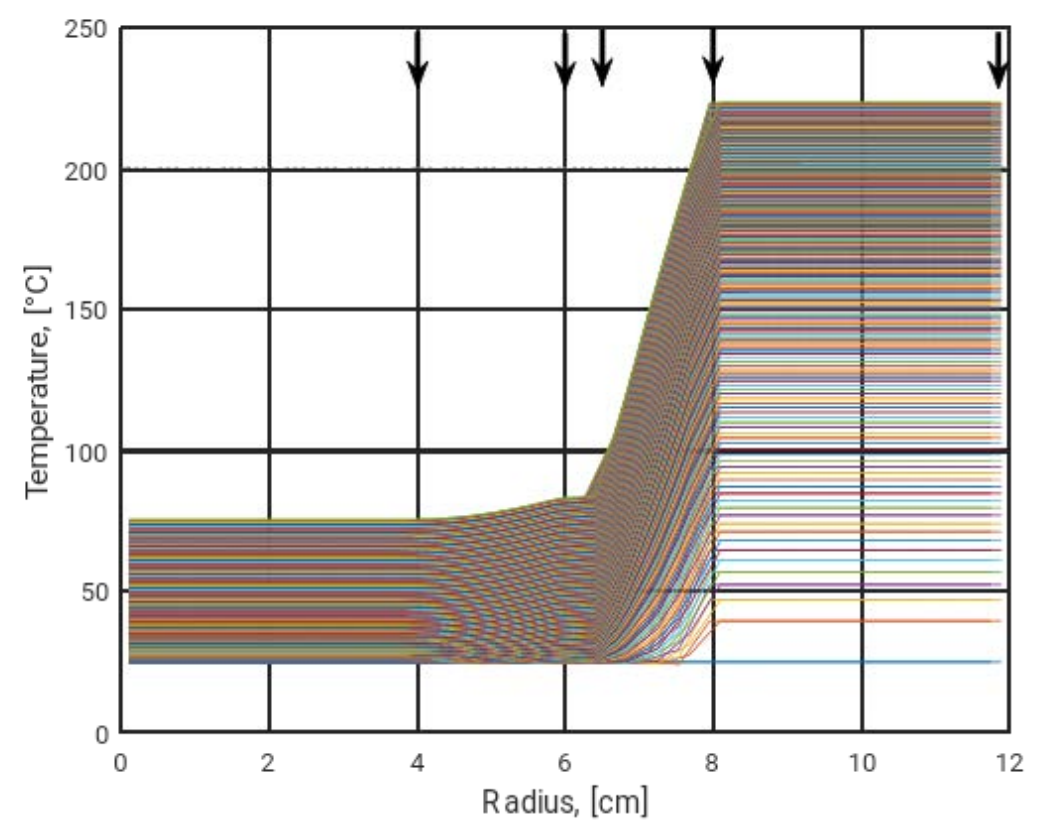

Figure 4. Temperature profiles after processing for $200 \mathrm{~s}$ with only the electrical resistance. Factor $f_{s 4}=4.2$. Arrows indicate the limit of each phase in the system

Source: Author

Figure 5 presents the temperature profiles after 5 and 200 seconds. As expected, the outermost layer (now called s4) reaches the highest temperature values. Moreover, and because of its relatively high thermal conductivity, temperature is constant throughout the thickness of this layer. The effect of the added layer is minimal. Even so, temperatures reached with only the electrical resistance are not high enough for the process (values remain between 50 and $280{ }^{\circ} \mathrm{C}$ ). 

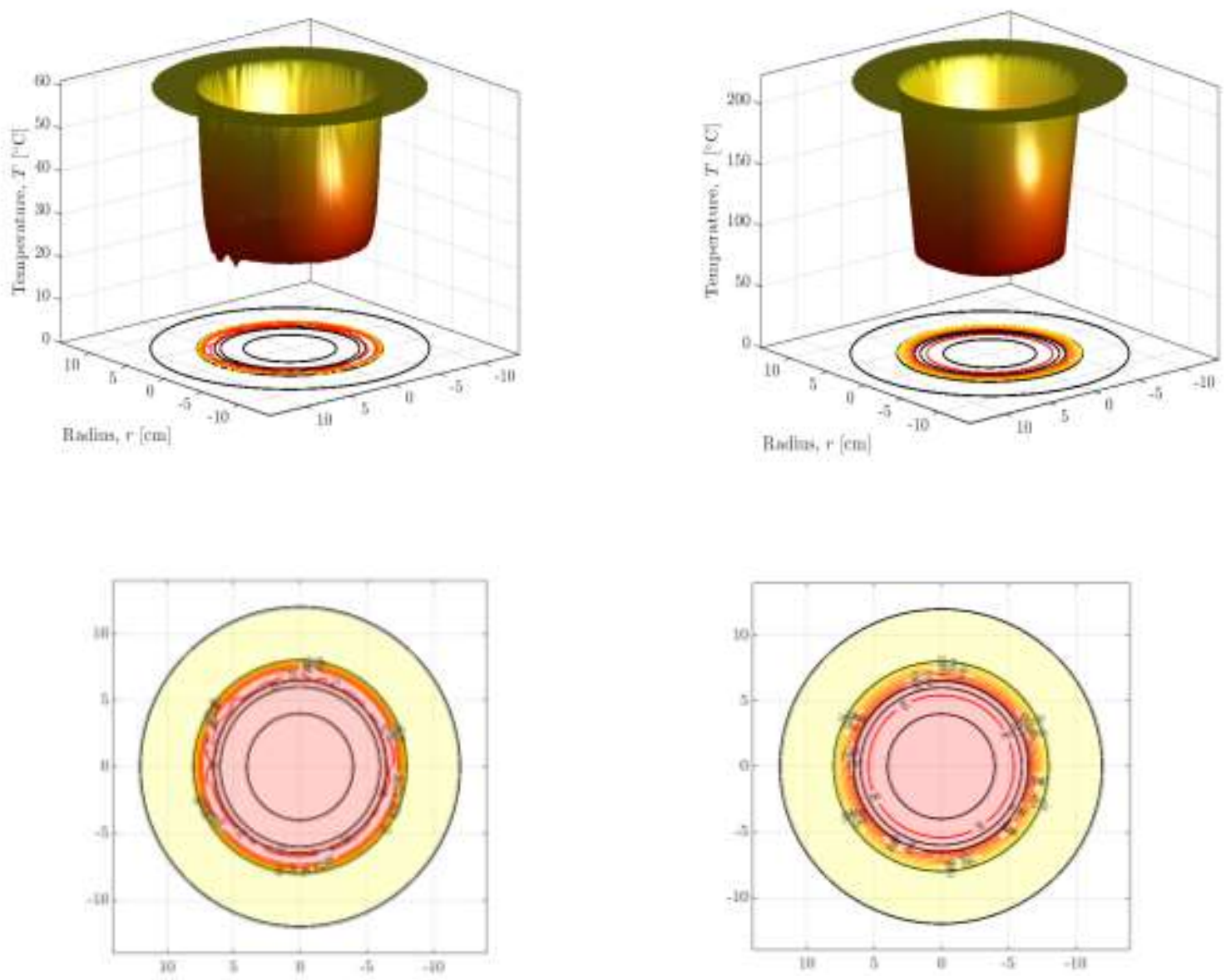

$5 \mathrm{~s}$

200s

Figure 5. Temperature profiles after processing for 5 (left) and 200 (right) seconds. Factor $f_{s 4}=4.2$ Source: Author

We now change factor $f_{s 4}$ striving to comply with temperature requirements. So, we increased it to $f_{s 4}=$ $4.2 \times 2$ (Figure 6). This time it is possible to reach a temperature of $410{ }^{\circ} \mathrm{C}$, but only in the external layer (the core only heats up to $120^{\circ} \mathrm{C}$ ). Additional simulations were performed with even higher values, but it was not possible to reach inner temperature values beyond $180{ }^{\circ} \mathrm{C}$. So, exclusively heating with the electrical resistance is out of the question. Thus, we move on to analyze the behavior of microwaves.

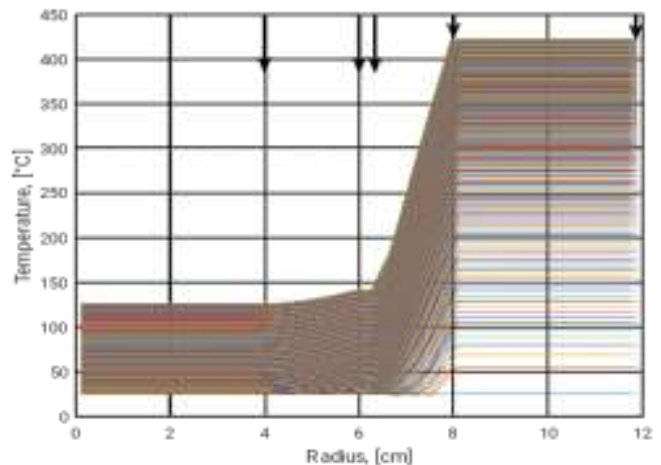

(a)

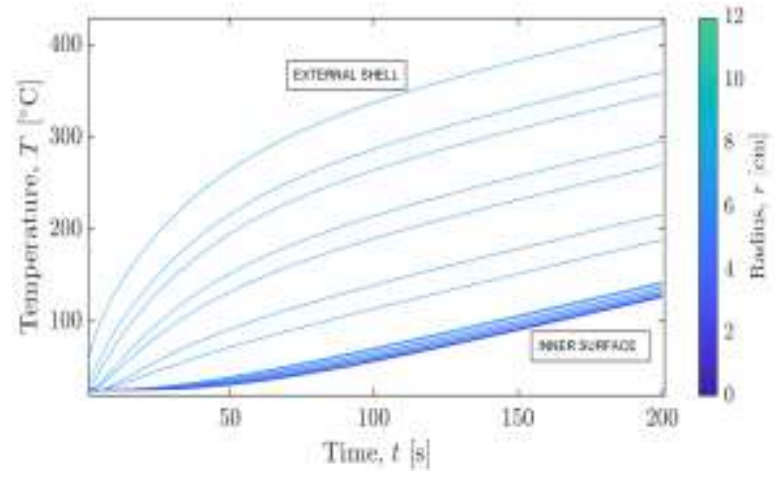

(b)

Figure 6. Temperature profiles as a function of radius (a) and processing time (b). The thin layer between $\mathrm{s} 1$ and $\mathrm{s} 3$ is included 


\section{Considering only the magnetron:}

If we consider the effect of heating only with microwaves, the core and the thin layer (s2) will be the ones that contribute to heating. For the former, microwave absorption is temperature independent, so the temperature profile is planar and only changes depending on factor $f_{1}$. Figure 7 shows there is a strong effect due to the low thermal conductivity of layers s1 and s3. Because the thin layer (s2) exists, temperature remains high, although not up to the point that the thermal process requires (even after $200 \mathrm{~s}$ ). The other layers heat due to thermal conduction.

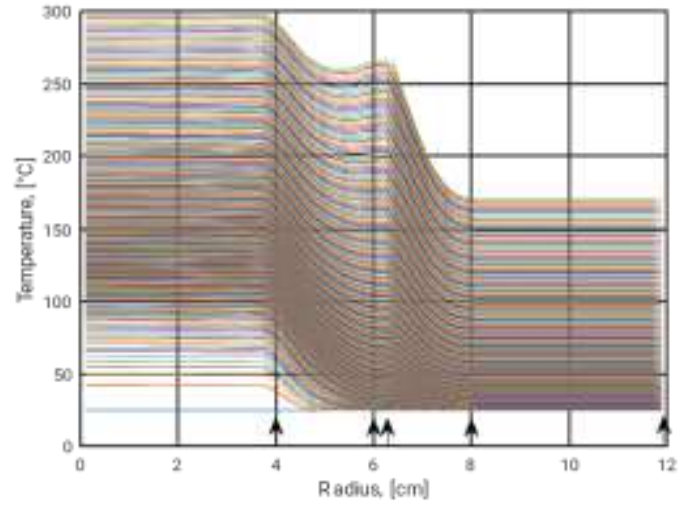

(a)

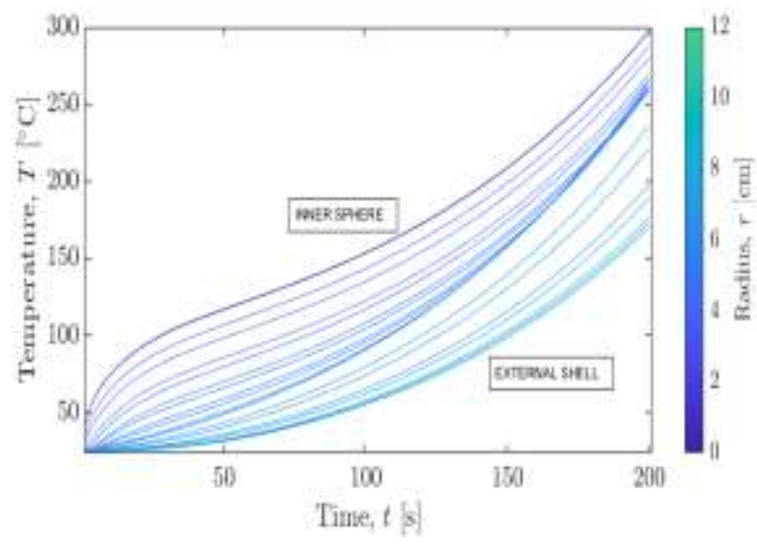

(b)

Figure 7. Temperature profiles as a function of radius (a) and processing time (b). Note the thermal response of the thin layer (s2). Arrows indicate the limits of each phase

Source: Author

We now increase factor $f_{1}$ up to $6.9 \times 2$ (Figure 8 ). The idea is to try and get closer to the required temperature profile. Since heating capabilities of layer s2 are temperature dependent, it will heat even more and following the function given in Table $1\left(f_{s 2}\right)$. Temperature profiles are the best ones so far, but the outermost layer (s4) still exhibits a temperature around $250{ }^{\circ} \mathrm{C}$, which is below the desired one (though constant). So, additionally heating with the electrical resistance should lead to a more planar profile within the required temperature range.
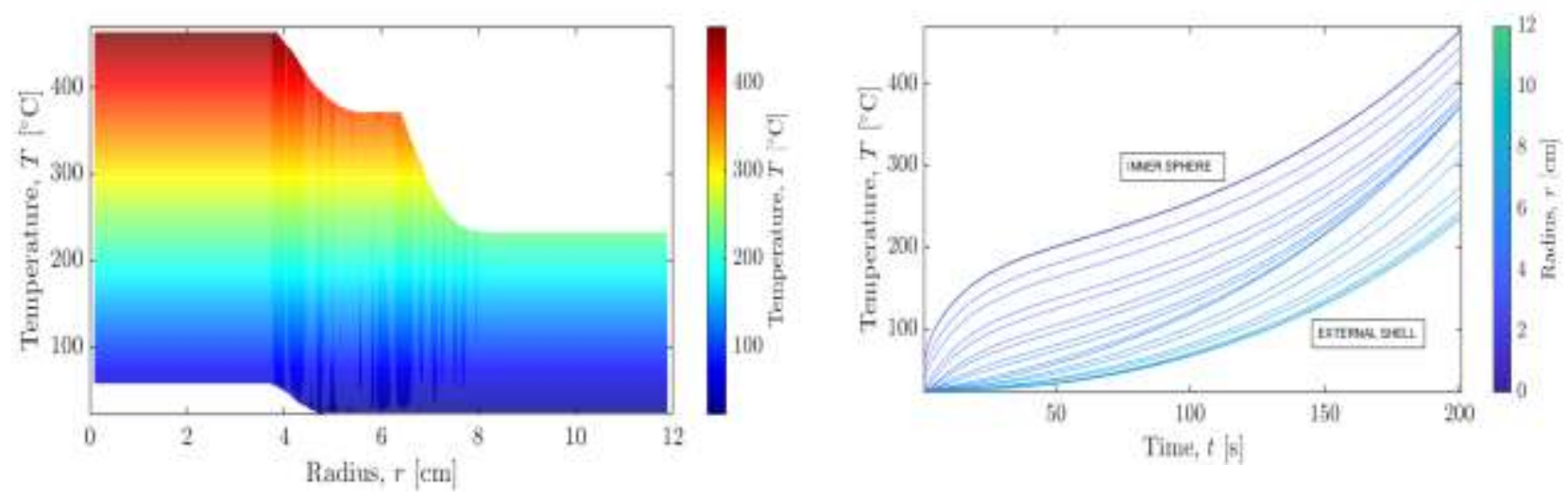

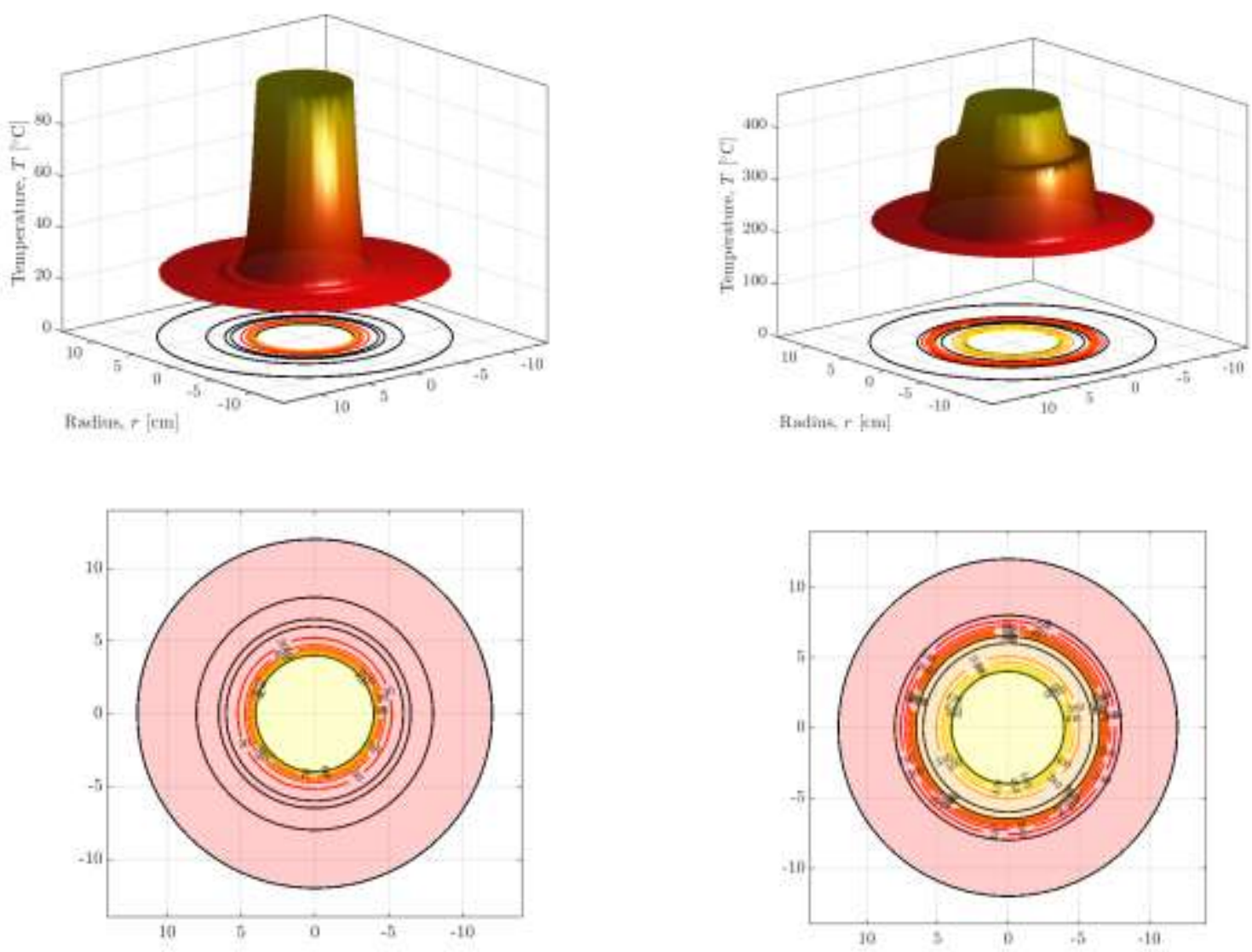

$5 \mathrm{~s}$

200s

Figure 8. Temperature profiles for $f_{1}=6.9 \times 2$. Details are also given for processing times of 5 and 200 seconds

Source: Author

\section{Considering the hybrid heating:}

Using both energy sources lead to a quick heating of the core and the thin layer (s2), as shown in Figure 9a. The reason for this are the nano-susceptors, since they strongly interact with microwaves. Similarly, the outermost layer (s4) heats because of the electrical resistance. Hence, the system reaches a homogeneous temperature via thermal conduction. Since a temperature between 370 and $410{ }^{\circ} \mathrm{C}$ is desired, the simulation also includes a system shutdown if a higher temperature is reached. Figure $9 \mathrm{~b}$ shows the variation of the temperature profile with time and position within the four shells that now surround the core.

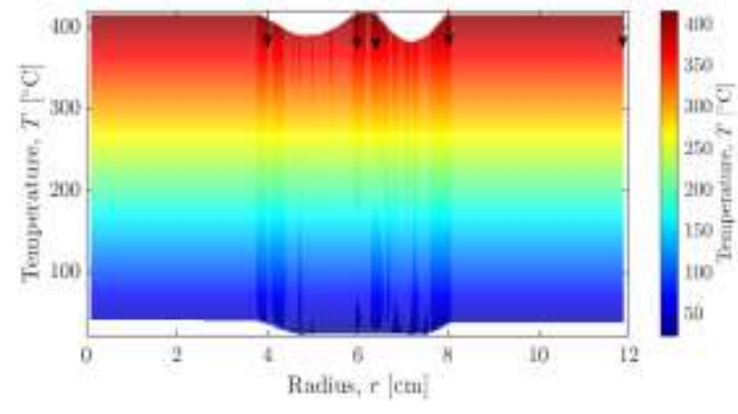

(a)

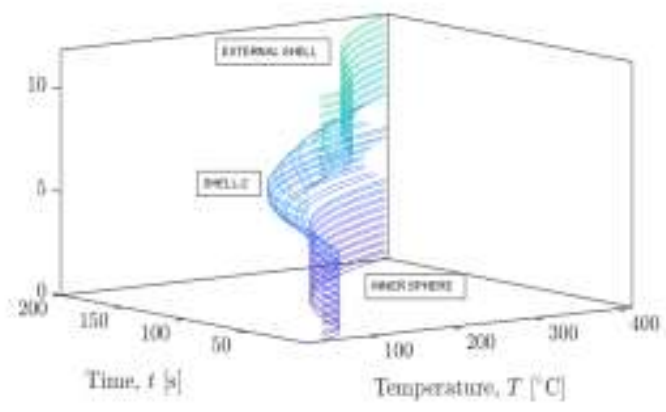

(b)

Figure 9. Temperature profiles for the hybrid heating in the core-shell system (four layers). Two sections preferentially absorb microwaves Source: Author 
Figure 10 details temperature profiles for arbitrarily selected time values (5, 100, 150, 200 seconds). Based on it and on Figure 9, it can be concluded that the system reached a temperature distribution that complies with thermal requirements. This is relevant since this effect was achieved in spite of the serious limitations linked to the low thermal conductivity of layers s1 and s3. Even if there may be other solutions and configurations, the one presented herein is feasible as it ensures that at least one solution exists for this thermal problem. Temperature profiles reach the required value after almost 200 seconds of processing.
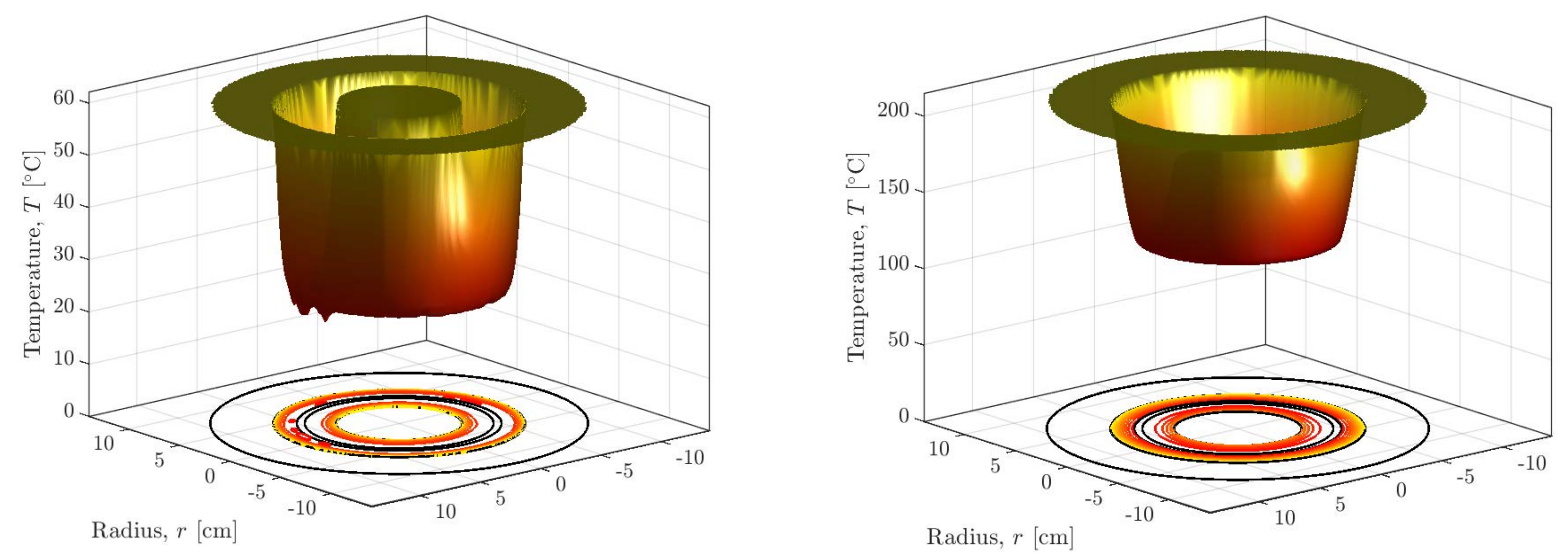

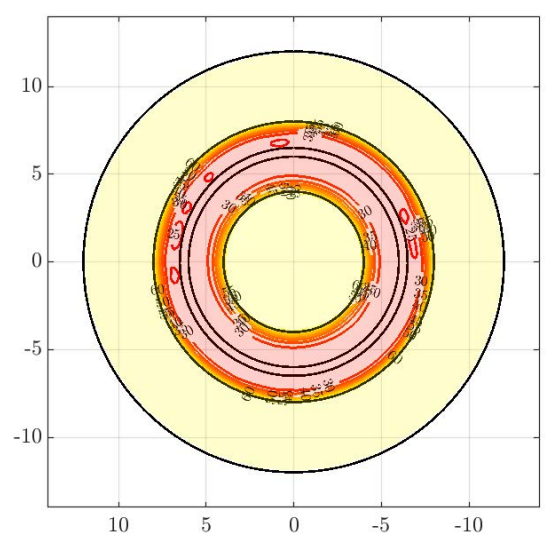

$5 \mathrm{~s}$

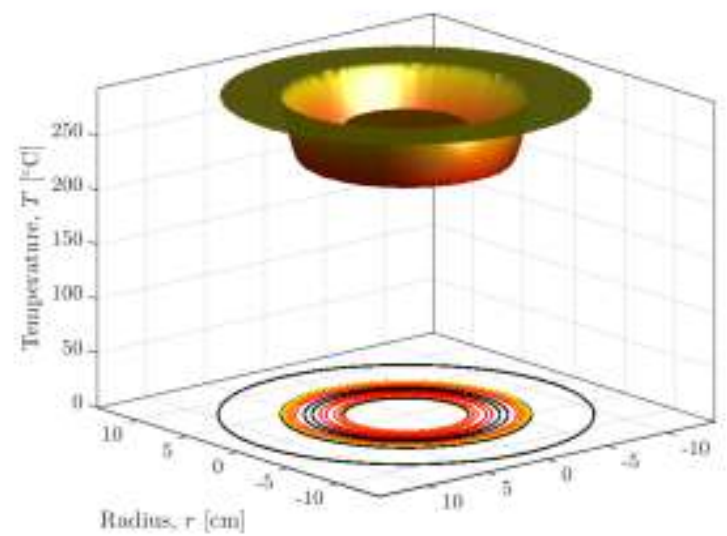

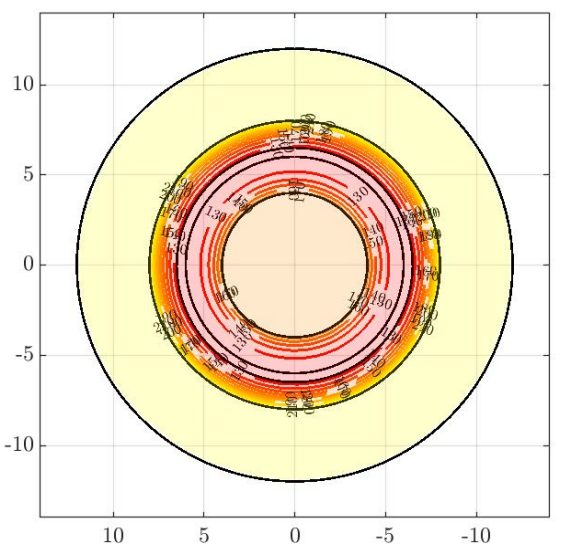

$100 \mathrm{~s}$

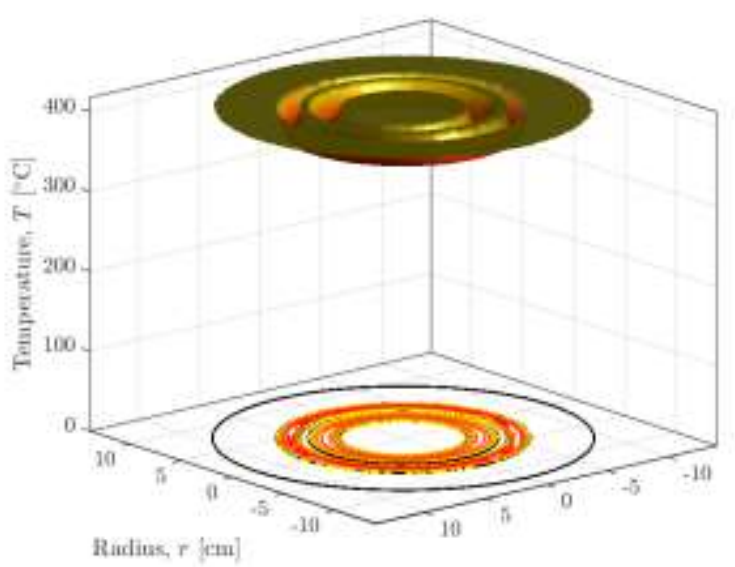




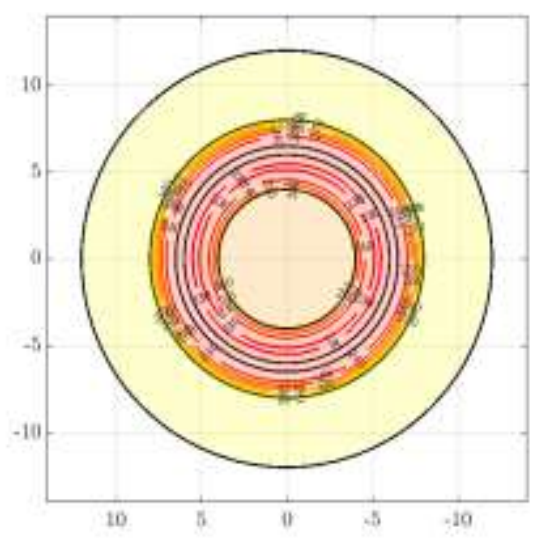

$150 \mathrm{~s}$

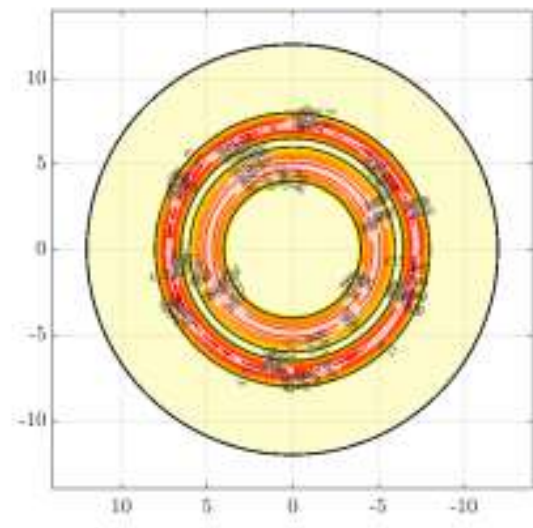

$200 \mathrm{~s}$

Figure 10. Temperature profiles throughout hybrid heating Fuente: Autor

\section{Conclusions}

In this work, we analyzed hybrid heating for a heterogeneous core-shell assembly. Such a heating approach is advantageous whenever it is necessary to treat composite materials, whose thermal and electrical properties vary abruptly across components. We followed a simulation-based approach since heating response to microwaves is quite sensitive to changes in dielectric properties. Hence, numerical modelling and experimentation is paramount for gathering data and analyzing the expected behavior of a system. This way, a designer can achieve better devices.

For the particular thermal situation we considered, hybrid heating turned out to be a good approach. The presence of two layers (s1 and s3) with low thermal conductivity inhibit the generation of homogeneous temperature profiles with each heating source by themselves. The result: an irregular thermal treatment across the system.

The proposed modifications allowed us to reach the required temperature range (i.e. $370-410{ }^{\circ} \mathrm{C}$ ) over the whole thermal system. Such modifications included changing the material of the core to a mixture with a susceptor material. A thin layer was also added as an interface between the first two shells. It is important to highlight that the solution to this kind thermal problem requires a continuously rotating system, as was demonstrated.

\begin{tabular}{|c|c|}
\hline Nomenclature & Greek symbols \\
\hline $\begin{array}{l}\text { B } \\
\text { Magnetic flux density, }\left(W b m^{-2}\right)\end{array}$ & $\begin{array}{l}\alpha_{i} \\
\text { Thermal diffusivity (component } i),\left(m^{2} s^{-1}\right)\end{array}$ \\
\hline $\begin{array}{l}c_{i} \\
\text { specific heat (component } i \text { ), } \mathrm{J} / \mathrm{kg} \mathrm{K}\end{array}$ & $\begin{array}{l}\varepsilon \\
\text { Permittivity, }\left(F m^{-1}\right)\end{array}$ \\
\hline $\begin{array}{l}\text { D } \\
\text { Electric flux density, }\left(\mathrm{C} \mathrm{m}^{-2}\right)\end{array}$ & $\begin{array}{l}\varepsilon_{0} \\
\text { Vacuum permittivity, }\left(8.854 \times 10^{-12} \mathrm{Fm}^{-1}\right)\end{array}$ \\
\hline$E$ & $\varepsilon_{e f}^{\prime \prime}$ \\
\hline Electric field intensity, $\left(\mathrm{V} \mathrm{m}^{-1}\right)$ & Effective dielectric loss factor, (dimensionless) \\
\hline $\begin{array}{l}E_{r m s} \\
\text { Local value of electric field magnitude, }\left(\mathrm{Vm}^{-1}\right)\end{array}$ & $\begin{array}{l}\varepsilon^{\prime}, \varepsilon^{\prime \prime} \\
\text { Real and imaginary permittivities, (dimensionless) }\end{array}$ \\
\hline $\begin{array}{l}f \\
\text { Incident wave frequency, }(\mathrm{Hz})\end{array}$ & $\begin{array}{l}\mu \\
\text { Permeability, }\left(\mathrm{H} \mathrm{m}^{-1}\right)\end{array}$ \\
\hline $\begin{array}{l}\mathbf{H} \\
\text { Magnetic field intensity, }\left(A \mathrm{~m}^{-1}\right)\end{array}$ & $\begin{array}{l}\mu_{0} \\
\text { Vacuum permeability, }\left(4 \pi \times 10^{-7} \mathrm{Fm}^{-1}\right)\end{array}$ \\
\hline $\begin{array}{l}H_{r m s} \\
\text { Local value of magnetic field magnitude, }\left(\mathrm{A} \mathrm{m}^{-1}\right)\end{array}$ & $\begin{array}{l}\mu_{e f}^{\prime \prime} \\
\text { Effective imaginary part of magnetic permeability, } \\
\text { (dimensionless) }\end{array}$ \\
\hline $\begin{array}{l}i \\
\text { Current intensity, }(A)\end{array}$ & $\begin{array}{l}\sigma \\
\text { Electric conductivity, }\left(\mathrm{S} \mathrm{m}^{-1}\right)\end{array}$ \\
\hline $\begin{array}{l}\mathbf{J} \\
\text { Electric current density, }\left(A \mathrm{~m}^{-2}\right)\end{array}$ & $\begin{array}{l}\rho_{i} \\
\text { Density (component } i),\left(\mathrm{kg} \mathrm{m}^{-3}\right)\end{array}$ \\
\hline $\begin{array}{l}k_{i} \\
\text { Thermal conductivity (component } i),(W / m K)\end{array}$ & $\begin{array}{l}\rho_{e} \\
\text { Electric charge density, }\left(\mathrm{C} \mathrm{m}^{-3}\right)\end{array}$ \\
\hline$P_{a v}^{\prime \prime \prime}(r ; \theta ; \phi ; t)$ & $\tan \delta(T)$ \\
\hline
\end{tabular}




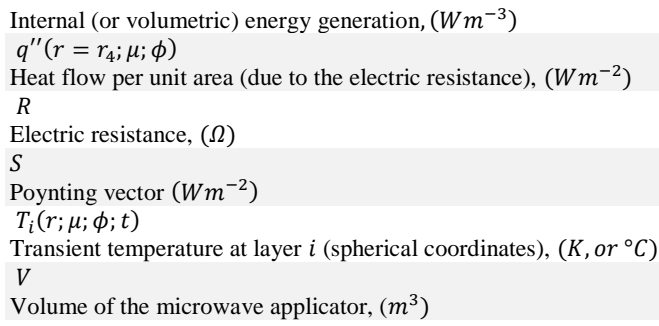

Funding: This study was funded by Universidad Industrial de Santander (Colombia), by Tecnologico de Monterrey (Mexico), and by Universidad Nacional de Colombia-Seccional Manizales

\section{Acknowledgments}

Authors would like to acknowledge the financial support given by Universidad Industrial de Santander (Colombia), by Tecnologico de Monterrey (Mexico), and by Universidad Nacional de Colombia-Seccional Manizales.

\section{References}

[1] J. Sun, W. Wang, and Q. Yue, "Review on Microwave-Matter Interaction Fundamentals and Efficient Microwave-Associated Heating Strategies”, Materials (Basel), vol. 9, no. 4, 2016.

[2] Z. Song et al., "Microwave drying performance of single-particle coal slime and energy consumption analyses", Fuel Processing Technology, vol. 143, pp. 69-78, 2016.

[3] W. Wang et al., "Quantitative measurement of energy utilization efficiency and study of influence factors in typical microwave heating process", ENERGY, vol. 87, pp. 678-685, 2015.

[4] R. Roy, R. Peelamedu, L. Hurtt, J. P. Cheng, and D. Agrawal, "Definitive experimental evidence for Microwave Effects: radically new effects of separated $\mathrm{E}$ and $\mathrm{H}$ fields, such as decrystallization of oxides in seconds", Materials Research Innovations, vol. 6, no. 3, pp. 128-140, 2002.

[5] K. Kashimura, H. Sugawara, M. Hayashi, T. Mitani, and N. Shinohara, "Microwave heating behavior and microwave absorption properties of barium titanate at high temperatures", AIP Advances, vol. 6, no. 6, 2016.

[6] H. Sugawara et al., "Temperature dependence and shape effect in high-temperature microwave heating of nickel oxide powders", Physica B: Condensed Matter, vol. 458, pp. 35-39, 2015.

[7] H. Zhu, T. Gulati, A. K. Datta, and K. Huang, "Microwave drying of spheres: Coupled electromagnetics-multiphase transport modeling with experimentation. Part I: Model development and experimental methodology", Food and Bioproducts Processing, vol. 96, pp. 314-325, 2015.

[8] A. J. Buttress et al., "Design and optimisation of a microwave reactor for kilo-scale polymer synthesis", Chemical Engineering Science: X, vol. 2, 2019.

[9] M. Kumar, D. M. Phase, and R. J. Choudhary, "Structural, ferroelectric and dielectric properties of multiferroic YMnO3 synthesized via microwave assisted radiant hybrid sintering”, HELIYON, vol. 5, no. $5,2019$.

[10] R. I. Badiger, S. Narendranath, and M. S. Srinath, "Optimization of Process Parameters by Taguchi Grey Relational Analysis in Joining Inconel-625 Through Microwave Hybrid Heating", 
Metallography, Microstructure, and Analysis (MMA), vol. 8, no. 1, pp. 92-108, 2019.

[11] N. M. Maliessa and S. R. A. Idris, "Effect of Different Amount of Silicon Carbide on SAC Solder-Cu Joint Performance by Using Microwave Hybrid Heating Method", IOP Conference Series: Materials Science and Engineering, vol. 469, no. 1, 2019.

[12] N. Chhanwal, P. R. Bhushette, and C. Anandharamakrishnan, "Current Perspectives on Nonconventional Heating Ovens for Baking Process-a Review”, Food and Bioprocess Technology, vol. 12, no. $1,2019$.

[13] S. L. Marahadige, S. M. Sridharmurthy, A. H. Jayraj, U. S. Mahabaleshwar, G. Lorenzini, and E. Lorenzini, "Development of copper alloy by microwave hybrid heating technique and its characterization", International Journal of Heat and Technology, vol. 36, no. 4, pp. 1343-1349, 2018.

[14] A. C. Meredith R. J.; Metaxas, “Industrial microwave heating”, Peter Peregrinus, 1993. 